\title{
Brain potentials of recollection and familiarity
}

\author{
TIM CURRAN \\ Case Western Reserve University, Cleveland, Ohio
}

\begin{abstract}
It is widely hypothesized that separate recollection and familiarity processes contribute to recognition memory. The present research measured event-related brain potentials (ERPs) from 128 head locations to identify patterns of brain activity related to recollection and familiarity. In two experiments, subjects performed a recognition memory task requiring discrimination between previously studied words, similar words that changed plurality between study and test, and new words (following Hintzman \& Curran, 1994). The FN400 ERP component (300-500 msec) varied with the familiarity of words (new $>$ studied = similar). The parietal component $(400-800 \mathrm{msec}$ ) was associated with the recollection of plurality (studied $>$ similar $=$ new). Differences in the timing and spatial topography of the FN400 and parietal effects support the view that familiarity and recollection arise from distinct neurocognitive processes.
\end{abstract}

Dual-process theories of memory posit that recognition judgments can be based on two different types of information: familiarity and recollection (Brainerd, Reyna, \& Kneer, 1995; Hintzman \& Curran, 1994; Jacoby, 1991; Mandler, 1980; Yonelinas, 1994). Familiarity is generally thought to reflect an assessment of the global similarity between studied and tested items (e.g., Clark \& Gronlund, 1996; Gillund \& Shiffrin, 1984; Hintzman, 1988; Humphreys, Bain, \& Pike, 1989; Murdock, 1982). Recollection entails the retrieval of specific information about studied items, such as physical attributes (Chalfonte \& Johnson, 1996; Hintzman \& Caulton, 1997; Hintzman \& Curran, 1994), associative/contextual information (Clark, 1992; Clark, Hori, \& Callan, 1993; Gronlund \& Ratcliff, 1989; Humphreys, 1978; Mandler, 1980; Yonelinas, 1997), or other source-specifying information (Hintzman, Caulton, \& Levitin, 1998; Jacoby, 1991; M. K. Johnson, Hashtroudi, \& Lindsay, 1993).

Recognition memory research has addressed two major questions regarding dual-process theories. First, does recognition memory truly depend on more than one process? In some cases, single-process theories can account for results that are commonly interpreted as requiring two processes (W. Donaldson, 1996; Hirshman \& Master, 1997; McClelland \& Chappell, 1998; Ratcliff, Van Zandt, \& McKoon, 1995; Shiffrin \& Steyvers, 1997). Second, if there are two processes, what are the characteristics of

\footnotetext{
The present research was supported by a W. P. Jones Faculty Development Award from Case Western Reserve University, a Research Initiation Grant from CWRU, and a grant from the McDonnell-Pew Program in Cognitive Neuroscience. The author thanks A. Daggy, A. David, A. Hills, J. Johnson, S. Klein, D. Marquardt, N. Meister, K. Raymond, D. Scott, R. Spinks, and J. Teichman for research assistance, Electrical Geodesics, Inc., for technical support, and S. Bentin, M. Besson, and D. Hintzman for helpful comments. Correspondence should be addressed to T. Curran, Department of Psychology, University of Colorado, Campus Box 345, Boulder, CO 80309-0345 (e-mail: tcurran@) psych.colorado.edu).
}

each process? Separating the distinct contributions of recollection and familiarity to recognition performance is difficult. Jacoby (1991) developed the process dissociation procedure for this purpose. Others have attempted to differentiate separate phenomenological states by asking subjects to introspectively differentiate "remembering" from "knowing" (reviewed by Gardiner \& Java, 1993; Rajaram \& Roediger, 1997). Others have used responsesignal, speed-accuracy tradeoff (SAT) procedures to separate fast familiarity from slower recollection processes (e.g., Hintzman \& Caulton, 1997; Hintzman et al., 1998; Hintzman \& Curran, 1994; McElree, Dolan, \& Jacoby, 1999). The utility of these approaches has been debated elsewhere: process dissociation (Curran \& Hintzman, 1995; Graf, 1995; Graf \& Komatsu, 1994; Jacoby, 1998; Jacoby, Begg, \& Toth, 1997; Joordens \& Merikle, 1993; Toth, 1995; Toth, Reingold, \& Jacoby, 1995), rememberknow (e.g., Donaldson, 1996; Gardiner, Ramponi, \& Richardson-Klavehn, 1998; Gardiner, RichardsonKlavehn, \& Ramponi, 1998; Hirshman, 1998; Hirshman \& Henzler, 1998; Hirshman \& Master, 1997), and SAT (Hintzman \& Curran, 1994; Rotello \& Heit, 1999).

Measuring event-related brain potentials (ERPs) during recognition memory tests could provide a useful alternative for estimating the contributions of recollection and familiarity. ERPs can be differentiated on the basis of their timing and scalp distribution, so different neurocognitive processes can be identified with distinct spatiotemporal voltage patterns. If the effects of familiarity and recollection were associated with distinct spatiotemporal ERP signatures, theories positing separate processes would be supported. If ERP signatures of recollection and familiarity can be identified, the functional characteristics of these processes can be explored by manipulating theoretically relevant variables.

Previous ERPs studies of recognition memory have been interpreted from dual-process perspectives. During recognition memory tests, ERPs differ between old (i.e., 
previously studied) and new (nonstudied) stimuli. Voltage recorded over parietal sites (relative to a mastoid reference) $400-800 \mathrm{msec}$ following stimulus onset is more positive for old stimuli than for new stimuli (for reviews, see R. J. Johnson, 1995, and Rugg, 1995). Previous studies suggest that the "parietal old/new effect"l is related to recollection (reviewed by Allan, Wilding, \& Rugg, 1998). When subjects are asked to introspectively differentiate words specifically "remembered" from those they merely "know" to be old, larger parietal old/new effects are associated with remembering than with knowing (Düzel, Yonelinas, Mangun, Heinze, \& Tulving, 1997; Rugg, Schloerscheidt, \& Mark, 1998; Smith, 1993). The parietal old/new effect is sensitive to variables thought to affect recollection more than familiarity (Paller \& Kutas, 1992; Paller, Kutas, \& McIsaac, 1995; Rugg, Cox, Doyle, \& Wells, 1995). The parietal old/new effect is associated with the recollection of specific information such as study modality (Wilding, Doyle, \& Rugg, 1995; Wilding \& Rugg, 1997b), speaker's voice (Rugg, Schloerscheidt, Doyle, Cox, \& Patching, 1998; Wilding \& Rugg, 1996, 1997a), and temporal source (Trott, Friedman, Ritter, \& Fabiani, 1997). Considerably less evidence has indicated any relationship between the parietal old/new effect and familiarity. Earlier studies suggested that word frequency interacted with the parietal old/new effect in a manner consistent with familiarity (Rugg, 1990; Rugg \& Doyle, 1992), but such word frequency effects have more recently been attributed to recollection (Rugg et al., 1995).

Behavioral evidence indicates that any ERP effects of familiarity should occur temporally prior to recollection effects. Hintzman and Curran (1994) asked subjects to study lists of singular and plural words (e.g., JAR, CATS). Subsequent recognition tests included studied words, highly similar words that changed plurality from study to test (e.g., JARS, CAT), and completely new words. Subjects were asked to recognize studied words and to reject similar and new words. A SAT procedure was used to study the temporal dynamics of memory retrieval (e.g., Dosher, 1984; Hintzman \& Curran, 1997; Reed, 1973). Subjects were signaled to make recognition judgments after unpredictable time lags $(100,200,350,500,750,1,200$, or $2,000 \mathrm{msec}$ ), and the time course of memory retrieval was estimated by tracking accuracy increases over time. Studied and similar words should be more familiar than new words, but recollection would be necessary to discriminate between studied and similar words (see also DiGirolamo \& Hintzman, 1997, Hintzman \& Curran, 1995, and Hintzman, Curran, \& Oppy, 1992). Subjects were first able to discriminate studied/similar items from new items at approximately $420 \mathrm{msec}$, but the ability to discriminate between studied and similar words did not emerge until approximately $540 \mathrm{msec}$. Thus, familiarity influenced recognition judgments approximately $120 \mathrm{msec}$ prior to plurality recollection. Other SAT studies have similarly found that discriminations that are likely familiarity based can be made prior to discriminations that are likely recollection based: studied versus rearranged sentences (Ratcliff \& McKoon, 1989), studied versus rearranged word pairs (Gronlund \& Ratcliff, 1989), modality (Hintzman \& Caulton, 1997), and list membership (Hintzman et al., 1998; McElree et al., 1999).

Assuming the parietal old/new effect is related to recollection, research using the SAT procedure clearly indicates that any ERP effects related to familiarity should occur earlier in processing. An earlier ERP old/new effect has been associated with the N400 ERP componentoriginally identified as an enhanced negativity in response to semantically incongruous words at the end of sentences (Kutas \& Hillyard, 1980; Kutas \& Van Petten, 1988). During recognition memory tests the $\mathrm{N} 400$ is more negative (at superior recording sites [e.g., $\mathrm{Pz}, \mathrm{Cz}$ ], relative to a mastoid reference) for new stimuli than for old stimuli (e.g., Friedman, 1990; Halgren \& Smith, 1987; NoldyCullum \& Stelmack, 1987; Smith \& Halgren, 1989).

Two recent studies have identified a frontal N400-like component (dubbed "FN400" by Curran, 1999) differing between old and new words that may be related to familiarity. ${ }^{2}$ Curran (1999) found that the FN400 old/new effect was similar for words and pseudowords, but the parietal old/new effect was substantially larger for words. If the FN400 reflects familiarity and the parietal old/new effect reflects recollection, these results would be consistent with introspective research indicating that remembering is more likely for words than for pseudowords (Curran, Schacter, Norman, \& Galluccio, 1997; Gardiner \& Java, 1990). Rugg, Mark, et al. (1998) identified a FN400 ERP old/new effect that did not differ between deeply and shallowly encoded words. In contrast, left parietal voltages $(500-800 \mathrm{msec})$ were more positive for deeply studied words than for shallowly studied words (replicating Paller \& Kutas, 1992, and Paller et al., 1995). Assuming that depth of processing influences recollection more than does familiarity (e.g., Gardiner, Java, \& Richardson-Klavehn, 1996; Toth, Reingold, \& Jacoby, 1994), Rugg, Mark, et al. (1998) suggested that the left parietal old/new effect indexes recollection, whereas the FN400 old/new effect may be related to familiarity.

The purpose of the present research was (1) to test the hypothesis that the FN400 old/new effect is related to familiarity and (2) to spatiotemporally differentiate any such familiarity effects from the parietal recollection effect. Previous research has suggested that the FN400 and parietal old/new effects are spatiotemporally distinct, so linking these ERP effects to familiarity and recollection would provide evidence for the separability of these neurocognitive processes. The present experiments were modeled after Hintzman and Curran's (1994) plurality recognition procedure. Subjects studied lists of singular and plural words followed by recognition tests with studied words, similar words with the opposite plurality, and completely new words. Subjects were instructed to respond "yes" to studied words and "no" to similar and new words. ERPs derived from trials in which subjects correctly said "yes" to studied words (studied[yes]) were assumed to reflect a mixture of processes associated with 
accurate plurality recollection and high familiarity. ERPs in the similar[yes] category were assumed to reflect high familiarity with minimal recollection of plurality. ERPs in the new[no] category were assumed to reflect low familiarity with minimal recollection. The ERP difference between studied[yes] and similar[yes] items should index effects of recollection (assuming familiarity is approximately equal between these conditions) that are predicted to correspond to the previously identified parietal old/ new effect. The ERP difference between similar[yes] and new[no] items should index effects of familiarity (assuming minimal recollection in either condition) that are predicted to influence the FN400 old/new effect.

\section{METHOD}

Two separate experiments were conducted to ensure that the results were reliable. The methods of Experiments 1 and 2 differed in only minor respects detailed below.

\section{Subjects}

The subjects were students at Case Western Reserve University Some subjects participated to satisfy a research requirement in introductory psychology, and others were paid $\$ 12$. All subjects were right-handed and native-English speakers. Thirty subjects participated in Experiment 1, and 42 subjects participated in Experiment 2. After rejecting the data of the subjects who had an insufficient number of artifact-free trials, 23 subjects were included in the analysis of Experiment 1 , and 29 subjects were included in the analysis of Experiment 2.

\section{Stimuli, Design, and Procedure}

Each 2-h experimental session began with a practice block ( 8 studied and 12 tested words) to instruct the subjects and acquaint them with the procedures. Following application of the Geodesic Sensor Net, the subjects completed four study-test blocks. Test conditions (studied, similar, new) were manipulated within blocks. Each subject completed 80 trials per condition ( 20 trials per condition per block).

Stimuli were 240 common concrete nouns that could be pluralized by adding an $s$. The words were divided into six counterbalancing lists that were roughly matched for mean length $(M=5.03$, $S D=0.82$, range $=4-6$ letters $)$ and word frequency $(M=15.90$, $S D=18.94$, range $=0-99$ occurrences per million; Kučera \& Francis, 1967). Words were counterbalanced across subjects so that each item appeared approximately equally in each condition. Another 36 words were used as practice and filler stimuli. Stimuli were presented on a 14-in. Apple Multiscan color monitor.

Stimulus timing differed between Experiments 1 and 2 for two reasons. First, study duration was decreased in Experiment 2 to increase the similar false-alarm rate and thereby increase the number of corresponding trials averaged into ERPs. Second, an Experiment 1 programming error changed event timing between Experiments 1 and 2 in two respects. Experiment 2 event timing was precisely synchronized with the refresh cycle of the subject's monitor ( 15 msec per cycle), but timing was not synchronized in Experiment 1 . Therefore, the actual timing of Experiment 1 events randomly varied from the desired timing ( $\pm 15 \mathrm{msec})$. The programming error also made the mean event times shorter than desired (as specified below). ${ }^{3}$

Each study list included 40 words (half singular, half plural) flanked by 1 untested word at the beginning and the end of the list. Each study word was visible for $871 \mathrm{msec}$ in Experiment 1 and $750 \mathrm{msec}$ in Experiment 2. A central plus sign (+) appeared between consecutive words (Experiment 1, $260 \mathrm{msec}$; Experiment 2,
$300 \mathrm{msec})$. The subjects were instructed to study each word and particularly memorize its plurality. A 2-min retention interval followed each study list.

Each test list contained 60 words: 20 studied, 20 similar, and 20 new. The plurality of similar words was switched between study and test lists ( 10 singular to plural, 10 plural to singular). New words did not appear on the study list in any form. Subjects were given a selfpaced rest break after every 15 words ( 5 trials per condition). Test order was random with the constraint that no more than three consecutive words came from the same condition. The subjects were instructed to press a "yes" key for studied words and a "no" key for similar and new words. Assignment of the right index and middle fingers to the "yes" and "no" categories was counterbalanced across subjects.

Each test trial began with a central plus sign $(+)$ for a variable duration (Experiment 1, 455 $871 \mathrm{msec}$; Experiment 2, 525 . $1,005 \mathrm{msec})$. The fixation was replaced by the test word for 1,729 msec (Experiment 1) or 1,995 msec (Experiment 2), which in turn was replaced by a central question mark (?). The question mark remained on the screen until the subject pressed a response key. An asterisk $\left({ }^{*}\right)$ appeared after the subject responded and remained visible throughout the $2-\mathrm{sec}$ interstimulus interval. EEG recording began either $429 \mathrm{msec}$ (Experiment 1) or $495 \mathrm{msec}$ (Experiment 2) prior to word onset and lasted for $2,000 \mathrm{msec}$. The subjects were instructed to wait for the question mark before responding, to remain as motionless as possible, and to minimize eye blinks.

\section{EEG Recording}

Scalp voltages were collected with a 128-channel Geodesic Sensor Net (Tucker, 1993) connected to an AC-coupled, 128-channel, high-input-impedance amplifier (200 $\mathrm{M} \Omega$, Net Amps, Electrical Geodesics, Inc., Eugene, OR). Amplified analog voltages (0.01$100 \mathrm{~Hz}$ bandpass) were digitized at $250 \mathrm{~Hz}$. Individual sensors were adjusted until impedances were less than $50 \mathrm{k} \Omega$.

\section{EEG Data Reduction}

Trials were discarded from analyses if they contained eye movements (vertical EOG channel differences greater than $70 \mu \mathrm{V}$ ) or more than five bad channels (changing more than $100 \mu \mathrm{V}$ between samples, or reaching amplitudes over $200 \mu \mathrm{V}$ ). ERPs from individual channels that were consistently bad for a given subject were replaced using a spherical interpolation algorithm (Srinivasan, Nunez, Silberstein, Tucker, \& Cadusch, 1996). The median number of excluded channels/subject was 1.00 for each experiment (Experiment 1, mode $=1$, range $=0-5 ;$ Experiment 2 , mode $=0$, range $=0-4)$. The subjects with less than 16 good trials in any condition were removed from the final analyses. The final number of subjects retained was 23 in Experiment 1 and 29 in Experiment 2.

ERPs were baseline-corrected with respect to the prestimulus recording interval and digitally low-pass filtered at $40 \mathrm{~Hz}$. An average-reference transformation was used to minimize the effects of reference-site activity and accurately estimate the scalp topography of the measured electrical fields (Bertrand, Perin, \& Pernier, 1985; Curran, Tucker, Kutas, \& Posner, 1993; Dien, 1998; Lehman \& Skrandies, 1985; Picton, Lins, \& Scherg, 1995; Tucker, Liotti, Potts, Russell, \& Posner, 1994). Average-reference ERPs were computed for each channel as the voltage difference between that channel and the average of all channels.

\section{RESULTS}

\section{Behavioral Results}

The subjects responded "yes" more often to studied items $(M=.66, S D=.11)$ than to similar items $(M=.41$, $S D=.11)$ [Experiment $1, t(22)=9.76$; Experiment 2 , $t(28)=7.43$; both $S E s=0.03, p s<.001]$. Thus, the sub- 


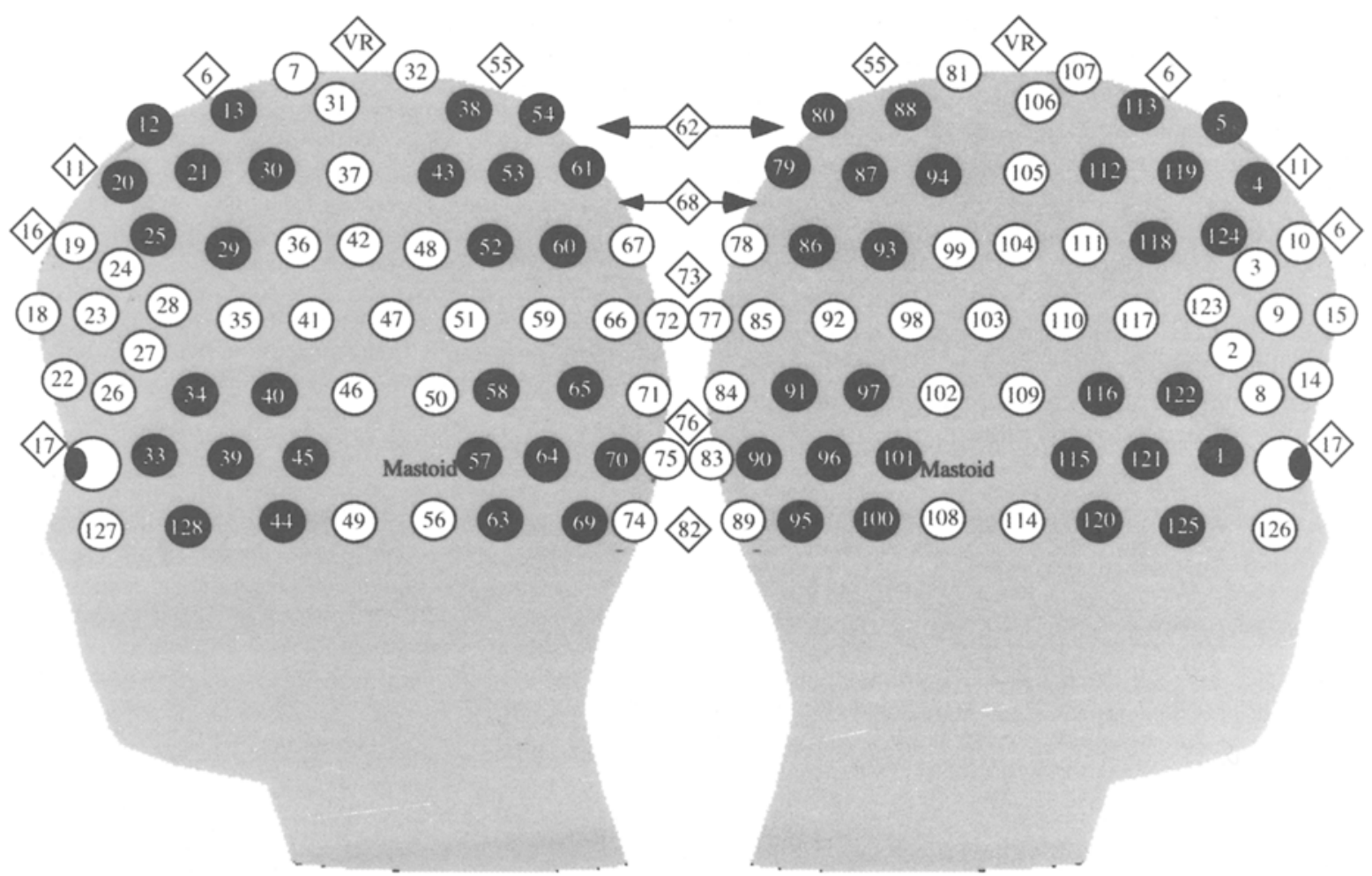

Figure 1. Sensor locations on the 128-channel Geodesic Sensor Net. The approximate sensor locations were projected onto a three-dimensional head model from which these two-dimensional images were taken. Sensors appear more closely spaced at the edges because depth is lost in the two-dimensional images, but actual electrode spacing is approximately equidistant throughout. Darker circles denote channels within each of the 8 spatial regions used in ANOVAs. Midline electrodes are denoted with diamond-shaped symbols. $V R=$ vertex reference.

jects demonstrated some ability to recollect the plurality of studied words. The false-alarm rate was significantly greater for similar words $(M=.41, S D=.11)$ than for new words $(M=.21, S D=.11)$ [Experiment $1, t(22)=8.50$; Experiment 2, $t(28)=9.54$; both $S E \mathrm{~s}=.02, p \mathrm{~s}<.001]$. These false-alarm rate differences are consistent with the expectation of higher familiarity for similar words than for new words.

\section{ERP Results}

Analysis strategy. The experimental design included words in three conditions (studied, similar, new) to which the subjects could respond either "yes" (studied) or "no" (not studied). ERPs were not computed from the new[yes] category because of an insufficient number of false alarms. ERPs from the studied[yes], similar[yes], similar[no], and new[no] category include all 52 subjects. ERPs from the studied[no] category include only the 44 subjects with at least 16 artifact-free misses (Experiment 1, $n=17$; Experiment 2, $n=27$ ). All figures represent the grand mean across both experiments, but separate statistical analyses were completed for each experiment. Repeated measures analyses of variance (ANOVAs) focused on mean amplitudes within specific temporal windows of interest $(300-500 \mathrm{msec}, 400$
$800 \mathrm{msec}, 1,000-1,500 \mathrm{msec}$ ). Only effects significant in each experiment separately were considered reliable. Effects involving spatial factors were reported only if they interacted with experimental conditions.

Analyses focused on eight scalp regions: 2 lateral (left, right) $\times 2$ caudal (anterior, posterior) $\times 2$ vertical (inferior, superior). Each region was a hexagonal group of seven electrodes (one central electrode and six at the vertices of the hexagon) that were selected to maximize interregion separation. Mean ERPs were computed across the channels within each region (see Figure 1). Primary analyses focused on regions and time windows in which the FN400 and parietal old/new effects have been maximal with the same high-density recording technique (Curran, 1999). ${ }^{5}$ For the FN400 old/new effect ( 300 $500 \mathrm{msec}$ ), ERPs to new stimuli were more negative than ERPs to old stimuli over anterior, superior (AS) regions (new $<$ old), but the opposite (new $>$ old) was true over posterior, inferior $(\mathrm{PI})$ regions. The parietal ERP old/new effect was maximal over posterior, superior (PS) regions (old $>$ new) and anterior, inferior (AI) regions (new $>$ old). Because surface-recorded potential fields are dipolar with equal positive and negative fields (Nunez, 1981), such reverse-polarity effects are expected when (1) the head surface is adequately sampled and (2) ERPs are 
computed with respect to the average reference. The ERP old/new differences recorded over superior regions were similar to those reported elsewhere (e.g., Rugg, Mark, et al., 1998), but opposite-polarity ERP differences are less likely to be recorded with typical procedures (e.g., less extensive inferior measurement and mastoid-referenced ERPs). From the present average-reference perspective, the "parietal" old/new effect can be described as a greater voltage difference between PS and AI regions for old items than for new items. The "FN400" old/new effect can be described as a greater voltage difference between $\mathrm{AS}$ and PI regions for new items than for old items. These effects are statistically indicated with condition (e.g., old, new) $\times$ region interactions. The parietal and FN400 labels have been retained to facilitate comparison with mastoidreferenced ERPs reported elsewhere. Mastoid-referenced ERPs are presented in the Appendix for comparison.

Specific ERP comparisons were guided by both practical and theoretical considerations. Comparisons between ERPs in the studied[yes], similar[yes], and new[no] categories were considered to provide the best available indices of recollection and familiarity processes. It was assumed that (1) the studied[yes] condition was associated with accurate plurality recollection and high familiarity, (2) the similar[yes] condition was associated with high familiarity and minimal recollection, and (3) the new[no] ERPs condition was associated with low familiarity and minimal recollection. ERPs from studied[yes] and new[no] categories - differing on both recollection and familiarity - were compared because they best approximate the old/new comparisons found in standard ERP recognition memory studies, but they are not specifically diagnostic of the component processes.

ERP differences between similar[yes] and new[no] categories were considered to primarily reflect familiarity effects because plurality recollection should be low in both cases. However, it could be argued that differences between these conditions are influenced by response choice differences (yes vs. no). Comparing new[no] with studied[no] or similar[no] categories would remove the response confound, but any "no" responses could result from a low-familiarity assessment. "No" responses to studied words (i.e., misses) are probably attributable to low familiarity because recollection is unlikely to cause mistaken rejection of highly familiar, studied words. For similar words, on the other hand, subjects may correctly reject highly familiar words when the opposite-plurality, studied words are recollected (Hintzman \& Curran, 1994). Therefore, similar[no] and new[no] differences should reflect familiarity effects-unconfounded with response choice. However, two problems remain with the similar[no]/new[no] comparison: (1) the comparison is subject to recollection differences, and (2) the comparison probably represents a smaller familiarity difference than the similar[yes]/new[no] comparison because similar items can also be rejected for low familiarity.

ERP differences between studied[yes] and similar[yes] categories were considered to be the primary index of recollection because both categories should be similarly familiar, yet recollection should be more prevalent for hits than for false alarms to similar items. A number of other comparisons are potentially related to recollection but are problematic in other respects. Recollection should be higher in similar[no] conditions than in studied[no] conditions, because correct rejection of similar item may occur when the plurality of the originally studied item is recollected (Hintzman \& Curran, 1994). However, familiarity should also differ between these conditions. Studied[no] items should be associated with low levels of both recollection and familiarity, whereas highly familiar similar[no] items would have been rejected when the opposite-plurality word is recollected. Therefore, comparing ERPs in similar[no] and studied[no] conditions confounds recollection and familiarity. Comparisons of correct versus incorrect responses within the studied (studied[yes] vs. studied[no]) and similar (similar[no] vs. similar[yes]) categories also should be influenced by recollection, but the comparisons are confounded by response choice. The "yes" versus "no" response confound is especially problematic for the parietal old/new effect, which encompasses the P300 (R. J. Johnson, 1995). The P300 is known to be sensitive to subjective probability (Duncan-Johnson \& Donchin, 1977; R. J. Johnson, 1988), and "no" responses were more frequent than "yes" responses in the present experiments.

In summary, it is hypothesized that FN400 amplitude is related to familiarity and that parietal amplitude is related to recollection. Familiarity effects will be primarily assessed by comparing ERPs in the similar[yes] and new[no] categories. Similar[no] and new[no] conditions will also be compared as a measure of familiarity that is unconfounded by response choice, but this comparison is confounded by recollect differences, and similar lures may be rejected because of low familiarity. Recollection effects will be primarily assessed by comparing ERPs in the studied[yes] and similar[yes] categories. Recollection should also contribute to ERP differences between similar[no] and studied[no] conditions, but this comparison is confounded by familiarity differences.

FN400 effects (300-500 msec). Curran (1999) found the FN400 old/new effect (i.e., the ERP difference between correctly classified old and new words) to be greatest over AS (new < old) and PI (new > old) channels from 300 to $500 \mathrm{msec}$, so the same spatiotemporal regions were included in the present analyses. The standard recognition comparison was tested in a condition (studied[yes], new [no]) $\times$ region $(\mathrm{AS}, \mathrm{PI}) \times$ laterality (left, right) ANOVA (see Figure 2). The conditions interacted across regions such that new words (mean amplitude across both experiments $=-1.18 \mu \mathrm{V}$ ) were more negative than studied words $(-0.69 \mu \mathrm{V})$ over AS regions, but the opposite effect (new [0.02 $\mu \mathrm{V}]>$ studied $[-0.34 \mu \mathrm{V}]$ ) appeared over PI regions (Experiment $1, F(1,22)=9.37$, $M S_{\mathrm{e}}=0.86, p<.01 ;$ Experiment $2, F(1,28)=6.28, M S_{\mathrm{e}}=$ $1.71, p<.05]$. Figure $3 \mathrm{~A}$ shows that the magnitude of this polarity reversal between AS and PI regions was 

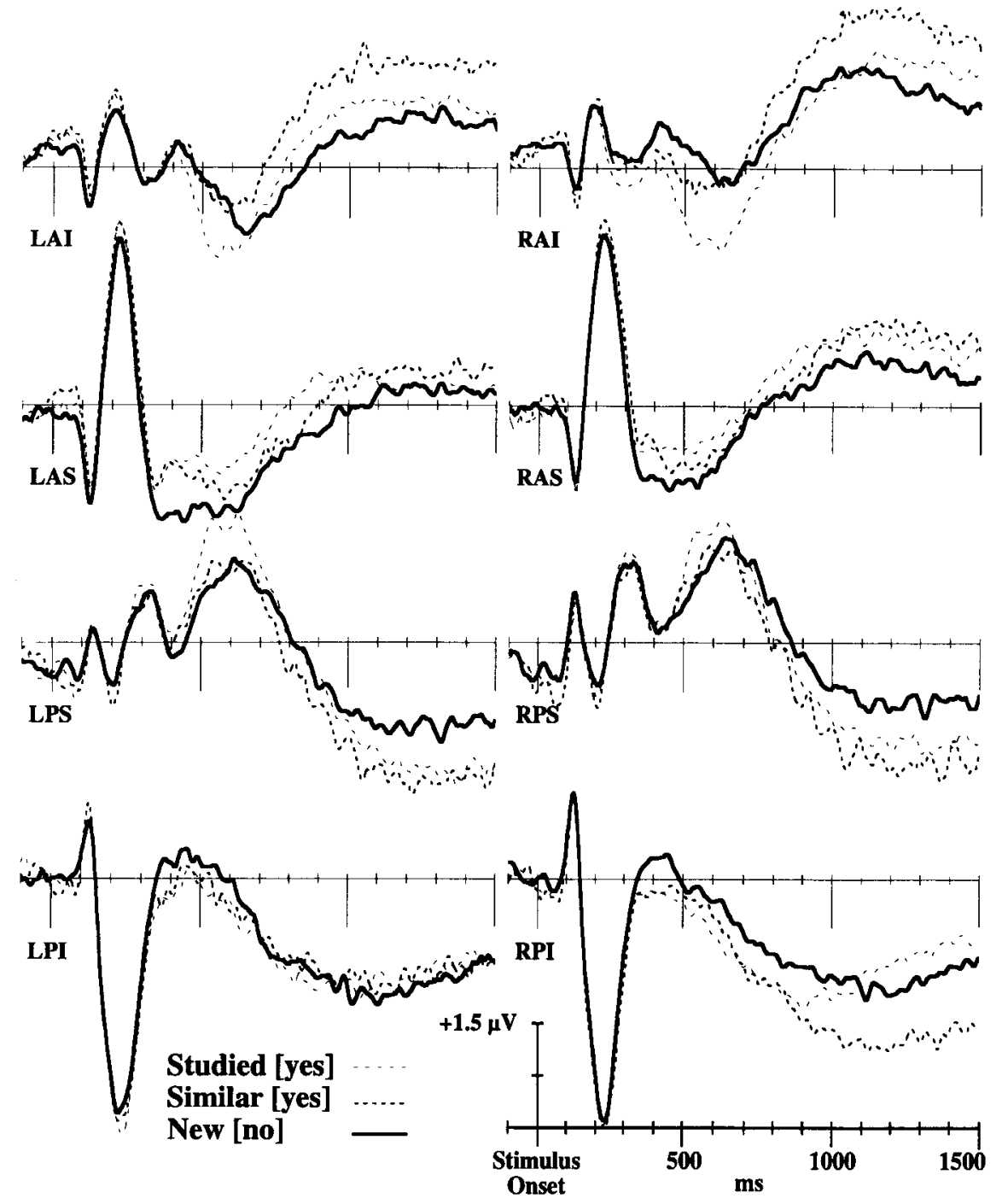

Figure 2. Average-referenced ERPs from the studied[yes], similar[yes], and new[no] conditions (Experiments 1 and 2 combined). Plotted ERPs are channel means within each of the eight spatial regions used for ANOVAs (see Figure 1). LAI = left, anterior, inferior; LAS = left, anterior, superior; LPS = left, posterior, superior; LPI = left, posterior, inferior; RAI = right, anterior, inferior; $\mathrm{RAS}=$ right, anterior, superior; $\mathrm{RPS}=$ right, posterior, superior; $\mathrm{RPI}=$ right, posterior, inferior.

greater in the new[no] condition than in the studied[yes] condition.

If, as hypothesized, the FN400 is specifically related to familiarity, differences should be observed between similar[yes] and new[no] conditions that differ primarily according to familiarity. The condition $\times$ region interaction indicated that the FN400 did vary between the similar[yes] and new[no] conditions [Experiment $1, F(1,22)=5.81$, $M S_{\mathrm{e}}=1.48, p<.05 ;$ Experiment $2, F(1,28)=6.46, M S_{\mathrm{e}}=$ $1.26, p<.05]$. The magnitude of the FN400 was larger in the low-familiarity new [no] condition (AS $=-1.18 \mu \mathrm{V}$; $\mathrm{PI}=0.02 \mu \mathrm{V})$ than in the high-familiarity similar[yes] condition (AS $=-0.70 \mu \mathrm{V} ; \mathrm{PI}=-0.30 \mu \mathrm{V})$.

If the FN400 effect is related to stimulus familiarity, it should not differ between studied[yes] (AS $=-0.69 \mu \mathrm{V}$;
$\mathrm{PI}=-0.34 \mu \mathrm{V})$ and similar[yes $](\mathrm{AS}=-0.70 \mu \mathrm{V} ; \mathrm{PI}=$ $-0.30 \mu \mathrm{V}$ ) conditions (see Figure $3 \mathrm{~A}$ ). Condition (studied[yes], similar[yes]) $\times$ region $(\mathrm{AS}, \mathrm{PI}) \times$ laterality (left, right) ANOVAs yielded no significant effects (for all effects involving condition, $F<1$ ).

Familiarity effects also should be observed when the similar[no] $(\mathrm{AS}=-0.72 \mu \mathrm{V} ; \mathrm{PI}=-0.36 \mu \mathrm{V})$ and new[no] (AS $=-1.18 \mu \mathrm{V} ; \mathrm{PI}=0.02 \mu \mathrm{V})$ conditions are compared (see Figure 4). A highly significant condition $\times$ region interaction was observed in Experiment 1 $\left[F(1,22)=20.39, M S_{\mathrm{e}}=1.26, p<.001\right]$, but the interaction was not replicated in Experiment $2[F(1,28)=1.47$, $\left.M S_{\mathrm{e}}=1.98\right]$.

Parietal effects (400-800 msec). Curran (1999) found parietal old/new effects (i.e., ERP differences be- 

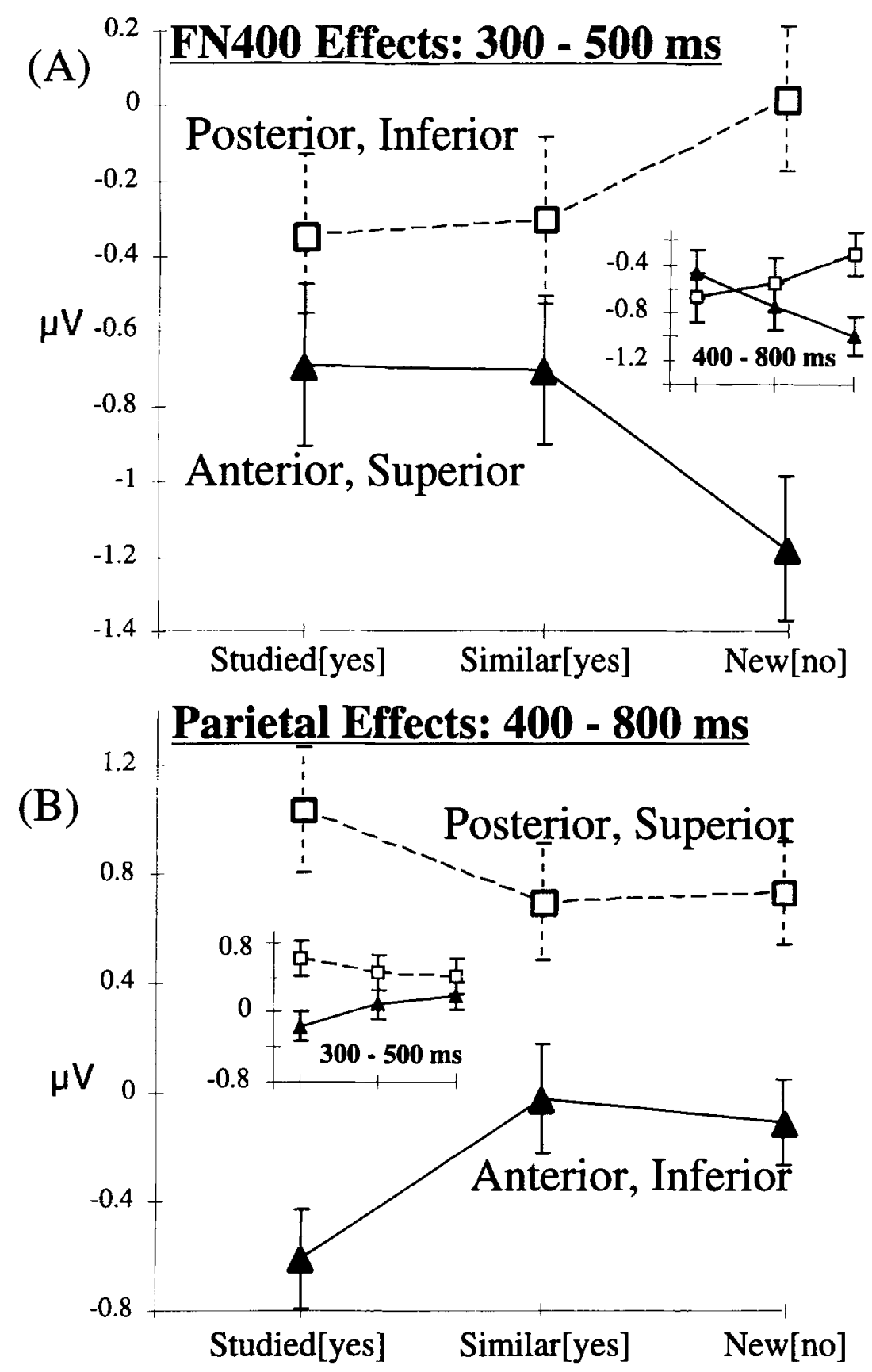

Figure 3. Mean voltage amplitudes ( $\pm S E$ ) associated with the principle experimental effects (Experiments 1 and 2 combined). (A) The main plot shows the posterior, inferior and the anterior, superior voltages during the FN400 window (300-500 msec). The small inset contains voltages in the same regions and conditions from 400 to $800 \mathrm{msec}$. (B) The main plot shows the posterior, superior and the anterior, inferior voltages during the parietal window ( $400-800 \mathrm{msec})$. The small inset contains voltages in the same regions and conditions from 300 to 500 msec.

tween correctly classified old and new words) to be maximal over PS (old > new) and AI (old $<$ new) regions between 400 and $700 \mathrm{msec}$. The present analyses were extended to $800 \mathrm{msec}$ to maintain consistency with other research describing parietal old/new effects, but results from 400 to $700 \mathrm{msec}$ were qualitatively similar. The stan- dard recognition comparison was tested in a condition (studied[yes], new [no]) $\times$ region $(\mathrm{AI}, \mathrm{PS}) \times$ laterality (left, right) ANOVA. The conditions interacted across regions such that studied[yes] ERPs $(M=1.04 \mu \mathrm{V})$ were more positive than new[no] ERPs $(0.73 \mu \mathrm{V})$ over PS regions, but the opposite pattern (studied $[-0.61 \mu \mathrm{V}]<$ 

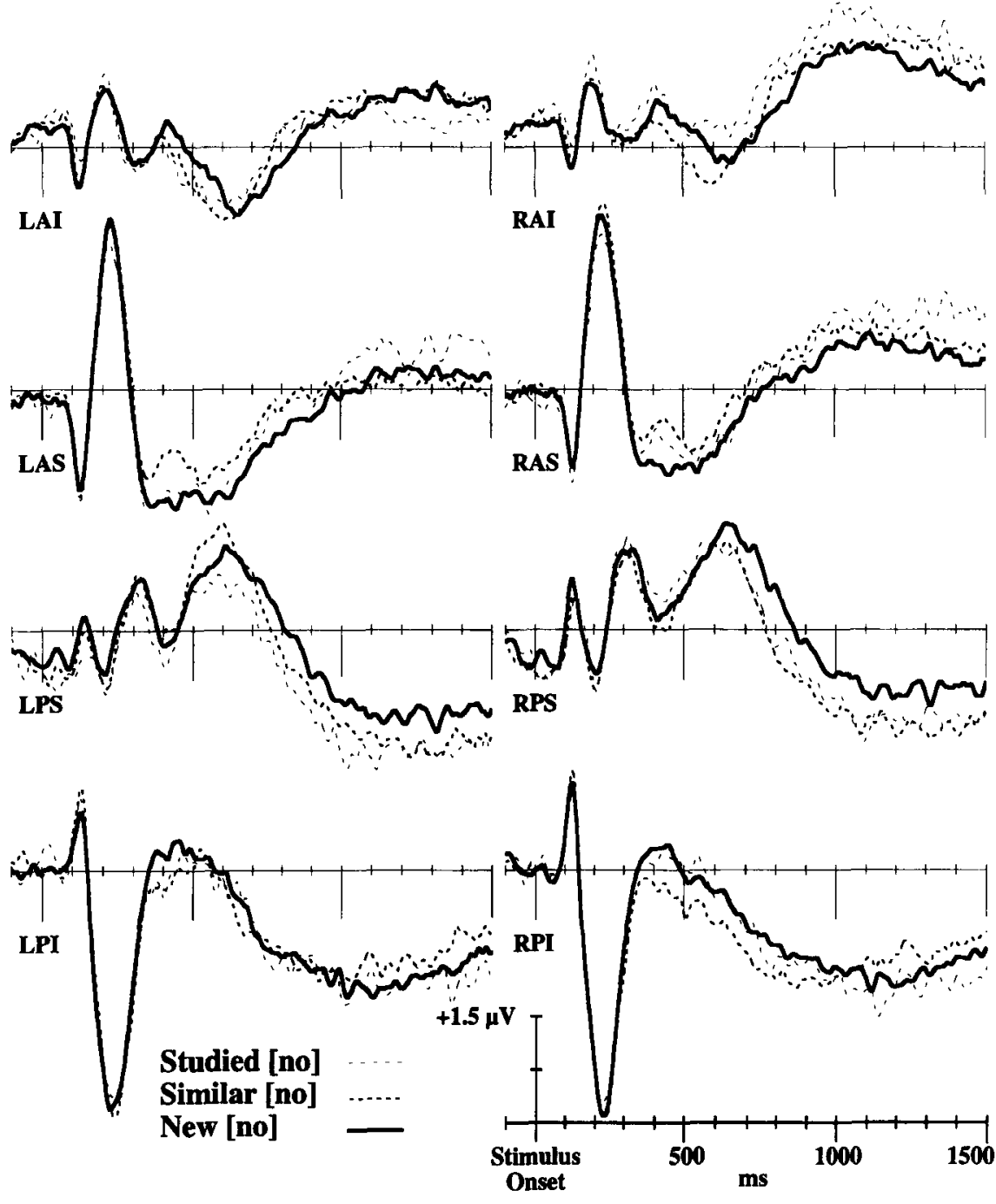

Figure 4. Average-referenced ERPs from the studied[no], similar[no], and new[no] conditions (Experiments 1 and 2 combined). Plotted ERPs are channel means within each of the eight spatial regions used for ANOVAs (see Figure 1). LAI = left, anterior, inferior; LAS = left, anterior, superior; LPS = left, posterior, superior; LPI = left, posterior, inferior; RAI = right, anterior, inferior; $\mathrm{RAS}$ = right, anterior, superior; RPS = right, posterior, superior; RPI = right, posterior, inferior.

new $[-0.11 \mu \mathrm{V}])$ held over AI regions [Experiment 1, $F(1,22)=4.45, M S_{\mathrm{e}}=0.98, p<.05$; Experiment 2 , $\left.F(1,28)=8.33, M S_{\mathrm{e}}=1.60, p<.01\right]$. In other words, the magnitude of polarity reversal between PS and AI regions was greater for the studied[yes] category than for the new[no] category (Figures 2 and 3B).

It was hypothesized that the parietal ERP old/new effect would be specifically related to the recollection of plurality, so differences should be observed between the studied[yes] and similar[yes] conditions. The condition $\times$ region interaction was marginally significant in $\mathrm{Ex}$ periment $1\left[F(1,22)=3.66, M S_{\mathrm{e}}=2.30, p<.07\right]$ and highly significant in Experiment $2[F(1,28)=17.50$, $\left.M S_{\mathrm{e}}=0.78, p<.001\right]$. Inspection of the $M S_{\mathrm{e}}$ in each ex- periment suggests that higher variability in Experiment 1 $\left(M S_{\mathrm{e}}=2.30\right)$ than in Experiment $2\left(M S_{\mathrm{e}}=0.78\right)$ contributed to the weaker effect in Experiment 1. Across both experiments combined, PS voltages were more positive for studied[yes] ERPs $(1.04 \mu \mathrm{V})$ than for similar[yes] ERPs $(0.70 \mu \mathrm{V})$, and AI voltages were more negative for studied[yes] ERPs $(-0.61 \mu \mathrm{V})$ than for similar [yes] ERPs $(-0.02 \mu \mathrm{V})$. Overall, these results support the hypothesis that the parietal old/new effect was larger for studied[yes] words that were recollected than for similar[yes] words that were not recollected (see Figure 3B). No differences were observed when similar[yes] and new[no] conditions were compared across the same spatial (PS, AI) and temporal $(400-800 \mathrm{msec})$ regions. The 
condition (similar[yes], new $[$ no] $) \times$ region $(\mathrm{PS}, \mathrm{AI})$ interaction did not approach significance in either experiment [Experiment 1, $F(1,22)<1, M S_{\mathrm{e}}=0.89$; Experiment $\left.2, F(1,28)<1, M S_{\mathrm{e}}=1.08\right]$.

Recollection should be more prevalent when the subjects correctly rejected similar items (similar[no]) than when they missed studied items (studied[no]), though, as previously explained, associated ERP differences may be obscured by familiarity differences (see Figure 4). These conditions were compared for the subset of subjects with sufficient studied[no] trials in condition (similar[no], studied[no]) $\times$ region $(A I, P S) \times$ laterality (left, right) ANOVAs. The condition $\times$ region interaction indicated that the parietal old/new effect was greater for rejected similar items than for missed studied items in Experiment $2\left[F(1,26)=6.08, M S_{\mathrm{e}}=2.16, p<.05\right]$, but not in Experiment $1\left[F(1,16)<1, M S_{\mathrm{e}}=1.59\right]$. In Experiment 2, PS voltages were more positive for similar[no] conditions $(M=1.06 \mu \mathrm{V})$ than for studied[no] conditions $(0.59 \mu \mathrm{V})$, and AI voltages were more negative for similar[no] conditions $(-0.43 \mu \mathrm{V})$ than for studied[no] conditions $(0.08 \mu \mathrm{V})$.

Topographic analyses. The foregoing analyses showed that the FN400 effects recorded over AS and PI regions were influenced by familiarity. The parietal effects recorded over PS and AI regions were associated with recollection. Further analyses were intended to evaluate topographic differences between the FN400 familiarity effect and the parietal recollection effect. ERP differences between similar[yes] and new[no] categories from 300 to $500 \mathrm{msec}$ were used to estimate familiarity effects. ERP differences between studied[yes] and similar[yes] categories from 400 to $800 \mathrm{msec}$ were used to estimate recollection effects. These ERP differences were normalized across the eight regional areas (left/right $\times$ anterior/ posterior $\times$ inferior/superior) according to McCarthy and Wood's (1985) vector length method. Normalization allows assessment of qualitative differences in scalp topography that are not influenced by the relative magnitude of the recollection and familiarity differences. A 2 difference (familiarity, similar[yes]-new[no], $300-500 \mathrm{msec}$; recollection, studied[yes]-similar[yes], $400-800 \mathrm{msec}) \times$ 2 left/right $\times 2$ anterior/superior $\times 2$ inferior/superior repeated measures ANOVA failed to detect any significant interactions between the normalized differences and any spatial factor. Thus, no qualitative differences were apparent between the scalp topographies of familiarity and recollection effects. The null result contrasts with earlier evidence that normalized FN400 and parietal old/ new differences interact across both the anterior/posterior and the inferior/superior dimensions (Curran, 1999).

The absence of topographic differences between recollection and familiarity effects is theoretically important because it represents a failure to provide evidence that the effects are produced by distinct neuronal populations. Evidence for distinct neural sources would support the idea that familiarity and recollection are the products of truly separate neurocognitive processes. One potential reason that topographic differences were lacking could be that activity originating from a single neuronal population shifts from an early familiarity-like pattern $(300-500 \mathrm{msec})$ to a later recollection-like pattern $(400$ $800 \mathrm{msec}$ ). Such a scenario may be better explained with a one-process account rather than a two-process account, but it is inconsistent with the entirety of the data. Figure $3 \mathrm{~A}$ shows the FN400 pattern from 300 to $500 \mathrm{msec}$, and its inset shows voltages over the same regions (AS, PI) from 400 to $800 \mathrm{msec}$. The inset demonstrates that later trends appear to exhibit a weaker form of the familiarity pattern that was statistically significant from 300 to $500 \mathrm{msec}$. Figure 3B shows the parietal pattern from 400 to $800 \mathrm{msec}$, and its inset shows voltages over the same regions (PS, AI) from 300 to $500 \mathrm{msec}$. In this case, the inset reveals the initial development of the recollection pattern that reached full strength between 400 and $800 \mathrm{msec}$. As a whole, Figure 3 indicates that activity across all scalp regions does not merely shift from an early $(300-500 \mathrm{msec})$ familiarity pattern to a later $(400-800 \mathrm{msec})$ recollection pattern. Rather, the familiarity pattern is most prominent over AS and PI regions (Figure $3 \mathrm{~A}$ ). The recollection pattern is most prominent over PS and AI regions (Figure $3 \mathrm{~B})$. However, there is considerable spatiotemporal overlap among these patterns that likely limited the sensitivity of the foregoing analyses to topographic differences between the effects.

To minimize the temporal overlap between the familiarity and recollection effects, smaller latency windows were computed around the peaks of the corresponding differences. The familiarity difference between similar[yes] and new[no] categories peaked at $376 \mathrm{msec}$, and the recollection difference between studied[yes] and similar[yes] categories peaked at $616 \mathrm{msec}$. Normalized differences were computed from 40 -msec windows surrounding these peaks and entered into a 2 difference (familiarity, similar[yes]-new[no], 356-396 msec; recollection, studied[yes]-similar[yes], 596-636 msec) $\times 2$ left/right $\times$ 2 anterior/superior $\times 2$ inferior/superior repeated measures ANOVA. The differences significantly interacted across the anterior/posterior dimension in Experiment 2 $\left[F(1,28)=5.24, M S_{\mathrm{e}}=0.33, p<.05\right]$, but the interaction only approached significance in Experiment $1[F(1,22)=$ $\left.2.53, M S_{\mathrm{e}}=0.28, p=.13\right]$. The corresponding topographic patterns are displayed in Figure 5. Figure 5 was constructed from the grand averages by computing ERP differences at each channel, interpolating the differences across a spherical model of the head, and projecting the interpolated image onto a three-dimensional head model. By scaling the data so that the maximum and minimum differences are pinned to the ends of the grayscale palette, the resultant images are roughly normalized between the familiarity (Figure 5A) and recollection (Figure 5B) effects. The difference $\times$ anterior/posterior interactions captured the observation that the 356-396-msec familiarity differences are more positive anteriorly than posteriorly, but the 596-636-msec recollection differences are more positive posteriorly than anteriorly. The interaction 

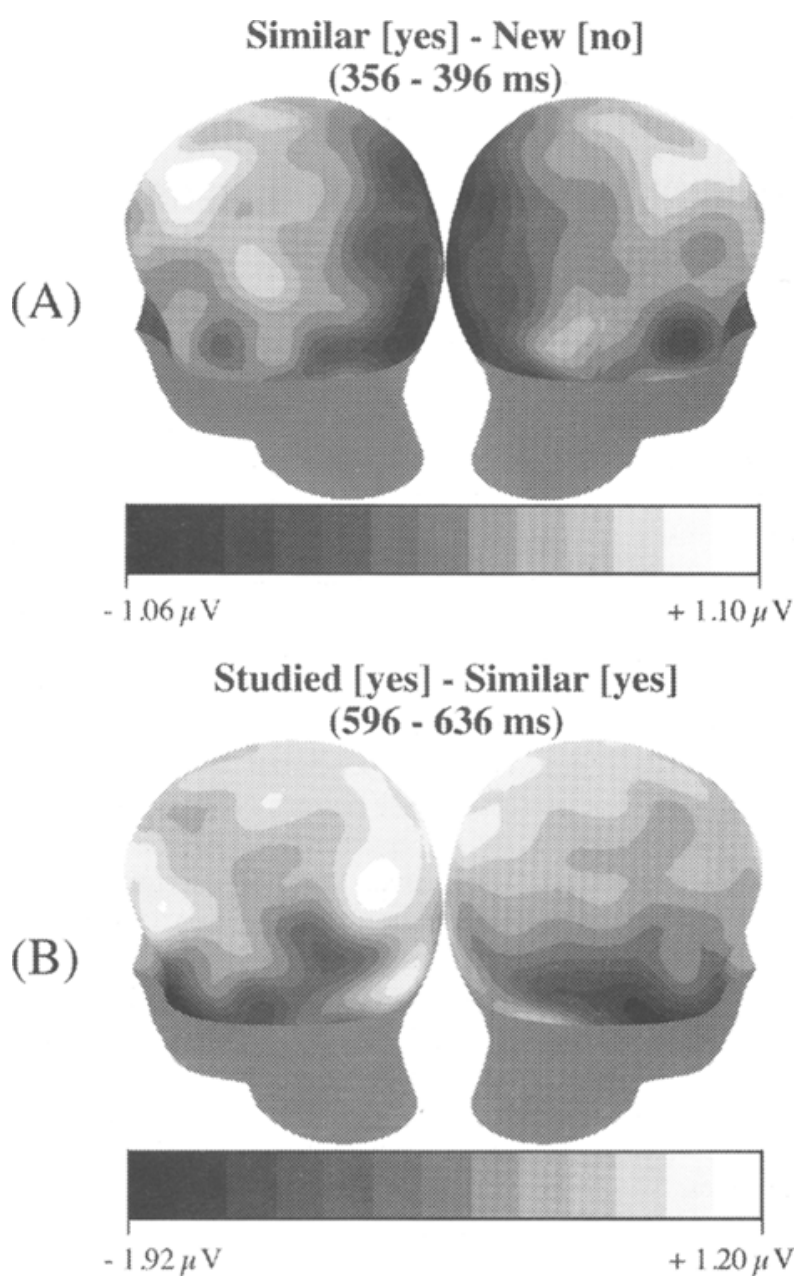

Figure 5. Topographic distributions of ERP effects associated with familiarity (A) and recollection (B). (A) Contours lines are plotted every $0.18 \mu \mathrm{V}$. (B) Contours lines are plotted every $0.26 \mu \mathrm{V}$.

did not reach statistical significance in Experiment 1 because the relatively weak and variable recollection effect led to less separation between anterior and posterior voltages.

Later effects $(1,000-1,500 \mathrm{msec})$. Differences between conditions were apparent between 1,000 and $1,500 \mathrm{msec}$ (see Figure 2). These effects were widely distributed, more variable between experiments than earlier effects, and likely to be response related. In the absence of a priori predictions, initial ANOVAs were computed across the three primary conditions (studied[yes], similar[yes], new[no]) and all regions (caudal $\times$ vertical $\times$ lateral). The only reliable effect involving condition was the condition $\times$ caudal interaction [Experiment $1, F(2,44)=$ $2.98, M S_{\mathrm{e}}=5.06, p=.07$; Experiment $2, F(2,56)=7.13$, $\left.M S_{\mathrm{e}}=3.31, p<.01\right]$. Late voltages were positive over anterior regions and negative over posterior regions, and the magnitude of this anterior/posterior reversal differed between the conditions.
Other ERP experiments related to source monitoring have described various late, frontal differences between conditions (M. K. Johnson, Kounios, \& Nolde, 1996; Senkfor \& Van Petten, 1998; Trott et al., 1997; Wilding et al., 1995; Wilding \& Rugg, 1996, 1997b). To compare the present plurality recollection effects with previously reported source recollection effects, differences among conditions were analyzed across the anterior regions alone. Anterior voltages were significantly more positive for the similar[yes] condition than for the new[no] condition [Experiment 1, $t(22)=2.76, S E=0.21, p=.05$; Experiment $2, t(28)=5.10, S E=0.13, p<.001]$, but no other pairwise contrasts were reliable. Though this could be interpreted as a familiarity effect, as above, this contrast is more likely to be confounded by response-related factors than earlier differences between these conditions.

\section{DISCUSSION}

The present experiments identified distinct ERP effects that are consistent with separate memory processes of familiarity and recollection. The subjects completed a recognition test with studied words, similar (oppositeplurality) words, and completely new words. FN400 amplitude (300-500 msec) was largest when the subjects correctly rejected new words (new[no]) than when they responded "yes" to studied or similar words. This FN400 effect is consistent with the activity of a process that is sensitive to experimental familiarity, because studied and similar words should both be more familiar than correctly rejected new words. The parietal effect $(400$ $800 \mathrm{msec}$ ) was larger for correctly recognized studied words (studied[yes]) than for falsely recognized similar words (similar[yes]). This parietal effect is consistent with the activity of a process related to recollection, because discriminating highly similar words requires the retrieval of detailed information from the study episode.

In addition to corroborating previous findings that familiarity processes act faster than recollection (Hintzman \& Caulton, 1997; Hintzman et al., 1998; Hintzman \& Curran, 1994; McElree et al., 1999), differing scalp distributions provided evidence for the separability of these processes (see Figure 5). The topography of the FN400 and parietal old/new effects replicated previous results using the same recording and analysis techniques (Curran, 1999). The FN400 effect showed a dipolar pattern over AS (new[no] < similar[yes]) and PI (new[no] > similar[yes]) regions. The parietal effect showed a dipolar pattern over PS (studied[yes] > similar[yes]) and AI (studied[yes] < similar[yes]) regions. Direct topographic comparisons of normalized recollection and familiarity effects were statistically significant in only one of the present experiments, but significant topographic differences between the FN400 and parietal old/new effects have been observed in previous research (Curran, 1999). The neuroanatomical separation of familiarity and recollection effects is theoretically important, because single-process models are sometimes able to account for behavioral ef- 
fects attributed to distinct familiarity and recollection processes (e.g., Donaldson, 1996; Hirshman \& Master, 1997; McClelland \& Chappell, 1998; Ratcliff et al., 1995; Shiffrin \& Steyvers, 1997). Therefore, the present results are consistent with dual-process accounts of recognition memory (Brainerd et al., 1995; Hintzman \& Curran, 1994; Jacoby, 1991; Mandler, 1980; Yonelinas, 1994).

Though the present evidence for neuroanatomic separability is compelling, other conceivable interpretations of the observed topographic patterns could be consistent with single-process explanations. Electrical fields originating from diffuse brain sources are volume conducted throughout head tissue so that all fields are superimposed in scalp recordings (Tucker et al,, 1994). A single memory process could contribute to both the FN400 and parietal old/new effects if topographic differences arose from the activity of different superimposed sources (possibly unrelated to memory) occurring at different times. However, such a single-process possibility does not readily explain differences between experimental effects on the FN400 and parietal old/new effects. As exemplified in Figure 3 , the results are not indicative of a topographically global shift from an early familiarity-like pattern to a late recollection-like pattern. Rather, the ERP signatures of recollection and familiarity were topographically distinct, yet temporally overlapping. The present differences in timing, topography, and sensitivity to experimental variables are all indicative of different memory processes.

A limitation of the present study concerns the fact that recollection estimates were based on only the attribute of plurality. Hintzman and Curran (1995) and Hintzman et al. (1992) showed that study-list repetition and encoding task manipulations similarly affect memory for word plurality and picture orientation, so plurality recognition results have generalized to other conditions. More important, for the present purposes, the influence of plurality recollection on the parietal old/new effect converges with other ERP studies that have used different criteria for inferring a relationship to recollection (reviewed by Allan \& Rugg, 1997). The parietal recollection effect is greater for "remembering" than for "knowing" (Düzel et al., 1997; Rugg, Schloerscheidt, \& Mark, 1998; Smith, 1993). The effect has been associated with the retrieval of various details, such as study modality (Wilding et al., 1995; Wilding \& Rugg, 1997b), speaker's voice (Rugg, Schloerscheidt, \& Mark, 1998; Wilding \& Rugg, 1996, 1997a), temporal source (Trott et al., 1997), and associative information (D. I. Donaldson \& Rugg, 1998; Rugg, Schloerscheidt, Doyle, Cox, \& Patching, 1996; Tendolkar, Doyle, \& Rugg, 1997). Other studies have found that the parietal recollection effect is influenced by variables that are presumed to affect recollection. The finding that depth of semantic processing influences the parietal old/new affect has been considered to be consistent with a relationship to recollection (Paller \& Kutas, 1992; Paller et al., 1995; Rugg, Mark, et al., 1998), although familiarity may also benefit from semantic processing (Toth, 1996). In comparing recognition memory for words and pseudo- words, words are associated with more "remembering" (Curran et al., 1997; Gardiner \& Parkin, 1990) and a larger parietal old/new effect (Curran, 1999).

A clear correlation has been established between recollection and the parietal old/new effect, but a better specification of the underlying cognitive processes is only beginning to emerge. The recollection of specific information likely involves various search, retrieval, and decision processes, as well as processes associated with the subjective experience of recollection. The relatively late time course of the parietal recollection effect suggests that it is not likely to underlie initial search and/or retrieval operations (Tendolkar et al., 1997). The correspondence between the parietal recollection effect and introspective "remembering" (Düzel et al., 1997; Rugg, Schloerscheidt, \& Mark, 1998; Smith, 1993) suggests a possible relationship to the subjective experience of recollection (also suggested by Paller et al., 1995). The parietal old/new effect did not differ between a recognition memory task in which subjects intentionally discriminated between old/new items and a lexical decision task in which old/new discrimination was incidental to task performance (Curran, 1999). Similarly, the parietal old/new effect was observed in an associative recognition task regardless of whether or not subjects were required to discriminate between intact and rearranged pairs (D. I. Donaldson \& Rugg, 1998). These findings (Curran, 1999; D. I. Donaldson \& Rugg, 1998) suggest that the parietal recollection effect does not depend on intentional retrieval strategies, so the effect may be related to involuntary aspects of conscious recollection (RichardsonKlavehn \& Gardiner, 1995; Richardson-Klavehn, Gardiner, \& Java, 1996; Schacter, 1987; Schacter, Bowers, \& Booker, 1989).

One theoretical question concerning recollection is the extent to which it contributes to recognizing studied items versus rejecting similar items (Clark \& Gronlund, 1996; Hintzman \& Curran, 1994; Rotello \& Heit, 1999). Hintzman and Curran (1994) found that "yes" responses to similar items increased early in retrieval (before about $540 \mathrm{msec}$ ), but later decreased. This biphasic pattern was interpreted as reflecting the initial effects of familiarity being counteracted by later recall of the opposite-plurality word that was actually studied. In Hintzman and Curran's (1999) SAT paradigm, differentiating familiarity and recollection was facilitated by placing the processes in opposition (e.g., Jacoby, 1991) so that familiarity would increase "yes" responses but recollection would increase "no" responses to similar items. SAT evidence that recollection aided recognition of studied words was less clear because "yes" responses to studied items would increase with both recollection and familiarity. Opposition was not as critical for differentiating recollection and familiarity with the present ERP method, and parietal voltage differences between studied[yes] and similar[yes] items suggest that recollection-related processes contribute to the recognition of studied items. Comparing similar[no] and studied[no] ERPs yielded mixed results concerning the contri- 
bution of recollection to the rejection of similar lures. The parietal effect was larger when the subjects responded "no" to similar items compared with studied items in Experiment 2, but not in Experiment 1. Because Experiment 2 converges with behavioral evidence that recollection does contribute to the rejection of similar lures (Hintzman \& Curran, 1994), the failure to identify associated ERP effects in Experiment 1 may be attributable to lower statistical power. Only 17 of 23 subjects had sufficient artifactfree studied[no] trials for inclusion in this comparison.

The relationship between recollection and the parietal old/new effect is supported by a wealth of converging evidence, but the relationship between the familiarity and the FN400 effect is less well established. The FN400 varied with familiarity when the three primary conditions were compared: new[no] > similar[yes] = studied [yes]. Differences between these conditions may be attributable to "yes" versus "no" response differences, so similar[no]/ new[no] differences were considered as a subsidiary estimate of familiarity effects. The FN400 differed between similar[no] and new[no] conditions in Experiment 1, but not in Experiment 2. The failure to obtain a similar[no]/ new[no] difference in Experiment 2 could indicate that differences between new[no] and similar [yes] conditions are attributable to response factors rather than familiarity, but this explanation cannot account for the significant effect in Experiment 1. The mixed results are consistent with familiarity differences being greater in the simi$\operatorname{lar}[$ yes] $/$ new[no] comparison than in the similar[no]/ new[no] comparison. The latter explanation must be true to some extent because similar[yes] items should be more familiar than similar[no] items.

It was reasoned that the similar[yes] condition should be associated with minimal recollection because the subjects would not have responded "yes" if the correct plurality was recollected. However, it should be acknowledged that ERPs in the similar[yes] condition might be affected by the recollection of information other than plurality. For example, a subject who studied "COOKIE" might incorrectly respond "yes" to the similar lure "COOKIEs" but clearly recollect that the word made him/her feel hungry during the study list. There are two primary reasons to doubt that recollection contributed to similar[yes]/new[no] ERP differences. First, given the wealth of evidence that the parietal ERP old/new effect is related to recollection, it is notable that no $400-800$ msec parietal differences were observed between the similar[yes] and new[no] conditions. If recollection of other study episode characteristics was prominent when the subjects falsely recognized similar words, the parietal recollection effects should have been observed in the similar[yes]/new[no]comparison. Second, if recollection contributed to the FN400 similar[yes]/new[no] differences, one would also expect FN400 differences between the studied[yes] and similar[yes] conditions. Despite these reasons to doubt that recollection of other attributes confounded the present results, future research should test the generalizability of the FN400 familiarity hypothesis under other conditions.

The parietal and FN400 old/new effects have been functionally dissociated in other recent experiments. The parietal old/new effect is greater for words than for pseudowords (Curran, 1999) and following deep encoding than following shallow encoding (Rugg, Mark, et al., 1998), but these studies observed FN400 old/new effects that were unaffected by the same variables. The present study indicates that the parietal old/new effect is not just generally more sensitive to memory-related variables than the FN400 effect, because similar[yes]/no[new] differences were observed for the FN400 effect but not the parietal effect. A recent ERP study requiring subjects to provide "remember" or "know" judgments to recognized words also suggests a link between familiarity and an N400like component recorded over temporal regions (Düzel et al., 1997). Subjects studied lists of semantically related words followed by a recognition test with studied items, semantically similar lures, and completely new words (following Deese, 1959; Roediger \& McDermott, 1995). An N400 recorded over temporal lobe locations was associated with "knowing" studied words and lures, but N400 amplitudes in both conditions were less negative than amplitude for correctly rejected new words.

In conclusion, the parietal and FN400 old/new effects appear to be associated with recollection and familiarity, respectively. The spatiotemporal separation of the FN400 familiarity and parietal recollection effects is consistent with separate underlying processes - as posited by dualprocess theories of recognition memory. These ERP scalp signatures of recollection and familiarity should serve as a useful tool for future research aimed at better understanding the functional characteristics of these processes.

\section{REFERENCES}

AllaN, K., \& RugG, M. D. (1997). An event-related potential study of explicit memory on tests of cued recall and recognition. Neuropsychologia, 35, 387-397.

Allan, K., Wilding, E. L., \& RugG, M. D. (1998). Electrophysiolog. ical evidence for dissociable processes contributing to recollection. Acta Psychologica, 98, 231-252.

Bentin, S., Mouchetant-Rostaing, Y., Giard, M. H., Echallier, J. F., \& PERNIER, J. (1999). ERP manifestations of processing printed words at different psycholinguistic levels: Time course and scalp distribution. Journal of Cognitive Neuroscience, 11, 235-260.

Bertrand, O., Perin, F., \& Pernier, J. (1985). A theoretical justification of the average reference in topographic evoked potential studies. Electroencephalography \& Clinical Neuroscience, 62, 462-464

Besson, M., Kutas, M., \& Van Perten, C. (1992). An event-related potentials (ERP) analysis of semantic congruity and repetition effect in sentences. Journal of Cognitive Neuroscience, 4, 132-149.

Brainerd, C. J., Reyna, V. F., \& KneER, R. (1995). False-recognition reversal: When similarity is distinctive. Journal of Memory \& Language, 34, 157-185.

Chalfonte, B. L., \& Johnson, M. K. (1996). Feature memory and binding in young and older adults. Memory \& Cognition, 24, 403416.

CLARK. S. E. (1992). Word frequency effects in associative and item recognition. Memory \& Cognition, 20, 231-243.

Clark, S. E., \& Gronlund, S. D. (1996). Global matching models of 
recognition memory: How the models match the data. Psychonomic Bulletin \& Review, 3, 37-60.

Clark, S. E., Hori, A., \& Callan, D. E. (1993). Forced-choice associative recognition: Implications for global-memory models. Journal of Experimental Psychology: Learning, Memory, \& Cognition, 19, $871-881$.

Curran, T. (1999). The electrophysiology of incidental and intentional retrieval: ERP old/new effects in lexical decision and recognition memory. Neuropsychologia, 37, 771-785.

Curran. T., \& HintzMan, D. L. (1995). Violations of the independence assumption in process dissociation. Journal of Experimental Psychology: Learning, Memory, \& Cognition, 21, 531-547.

Curran, T., Schacter, D. L., Norman, K. A., \& Galluccio, L. (1997). False recognition after a right frontal lobe infarction: Memory for general and specific information. Neuropsychologia, 35 , 1035-1049.

Curran, T., Tucker, D. M., Kutas, M., \& Posner, M. I. (1993) Topography of the N400: Brain electrical activity reflecting semantic expectation. Electroencephalography \& Clinical Neurophysiology, 88, 188-209.

DEESE, J. (1959). On the prediction of occurrence of particular verbal intrusions in immediate recall. Journal of Experimental Psychologv, 58, 17-22.

DIEN, J. (1998). Issues in the application of the average reference: Review, critiques, and recommendations. Behavior Research Methods Instruments, \& Computers, 30, 34-43.

DiGirolamo, G. J., \& Hintzman, D. L. (1997). First impressions are lasting impressions: A primacy effect in memory for repetitions. $P_{s y-}$ chonomic Bulletin \& Review, 4, 121-124.

Donaldson, D. I., \& RugG, M. D. (1998). Recognition memory for new associations: Electrophysiological evidence for the role of recollection. Neuropsychologia, 36, 377-395.

Donaldoson, $W$. (1996). The role of decision processes in remembering and knowing. Memory \& Cognition, 24, 523-533.

DOSHER, B. A. (1984). Degree of learning and retrieval speed: Study time and multiple exposures. Journal of Experimental Psychology: Learning. Memory, \& Cognition, 10, 541-574.

DunCan-Johnson, C. C., \& Donchin, E. (1977). On quantifying surprise: The variation of event-related potentials with subjective probability. Psvchophvsiology, 14, 456-467.

Düzel, E., Yonelinas, A. P., Mangun, G. R., Heinze, H.-J., \& Tul VING, E. (1997). Event-related potential correlates of two states of conscious awareness in memory. Proceedings of the National Academy of Sciences, 94, 5973-5978.

Friedman, D. (1990). Cognitive event-related potential components during continuous recognition. Psychophysiology, 27, 136-148.

GardinER, J. M., \& JAVA, R. I. (1990). Recollective experience in word and nonword recognition. Memory \& Cognition, 18, 23-30

GARDINER, J. M.. \& JAVA, R. I. (1993). Recognising and remembering. In A. F. Collins, M. A. Gathercole, M. A. Conway, \& P. E. Morris (Eds.), Theories of memorv (pp. 163-188). Hove, U.K.: Erlbaum.

Gardiner, J. M., Java, R. I., \& Richardson-Klavehn, A. (1996). How level of processing really influences awareness in recognition memory. Canadian Journal of Experimental Psychology, 50, 114 122.

Gardiner. J. M., \& Parkin, A. J. (1990). Attention and recollective experience in recognition memory. Memory \& Cognition, 18, 579-583.

Gardiner, J. M., Ramponi, C., \& Richardson-Klavehn, A. (1998). Experiences of remembering, knowing, and guessing. Consciousness \& Cognition, 7, 1-26.

Gardiner, J. M., Richardson-Klavehn, A., \& Ramponi, C. (1998). Limitations of the signal detection model of the remember-know paradigm: A reply to Hirshman. Consciousness \& Cognition, 7, 285288.

Gillund, G., \& ShifFrin, R. M. (1984). A retrieval model for both recognition and recall. Psychological Review, 91, 1-67.

GRAF, P. (1995). Defining the opposition procedure: A reply to Toth, Reingold and Jacoby's (1995) response to Graf and Komatsu (1994). European Journal of Cognitive Psychology, 7, 225-231.
Graf, P., \& Komatsu, S. (1994). Process dissociation procedure: Handle with caution! European Journal of Cognitive Psychology, 6, 113-129.

Gronlund, S. D., \& RatclifF, R. (1989). Time course of item and associative information: Implications for global memory models. Journal of Experimental Psychology: Learning, Memory, \& Cognition, 15, 846-858

Halgren, E., \& SMith, M. E. (1987). Cognitive evoked potentials as modulatory processes in human memory formation and retrieval. Human Neurobiology, 6, 129-139.

HinTZMan, D. L. (1988). Judgments of frequency and recognition memory in a multiple-trace memory model. Psychological Review, 95, 528-551

Hintzman, D. L., \& Caulton, D. A. (1997). Recognition memory and modality judgments: A comparison of retrieval dynamics. Journal of Memory \& Language, 37, 1-23.

Hintzman, D. L., Caulton, D. A., \& Levitin, D. J. (1998). Retrieval dynamics in recognition and list discrimination: Further evidence of separate processes of familiarity and recall. Memory \& Cognition, 26, 449-462.

Hintzman, D. L., \& CurRan, T. (1994). Retrieval dynamics of recognition and frequency judgments: Evidence for separate processes of familiarity and recall. Journal of Memory \& Language, 33, 1-18.

Hintzman, D. L., \& CuRRaN, T. (1995). When encoding fails: Instructions, feedback, and registration without learning. Memory \& Cognition, 23, 213-226.

Hintzman, D. L., \& Curran, T. (1997). Comparing retrieval dynamics in recognition memory and lexical decision. Journal of Experimental Psychology: General, 126, 228-247.

Hintzman, D. L., Curran, T., \& OpPy, B. (1992). Effects of similarity and repetition on memory: Registration without learning? Journal of Experimental Psychology: Learning, Memory, \& Cognition, 18, 667. 680.

Hirshman, E. (1998). On the utility of the signal detection model of the remember-know paradigm. Consciousness \& Cognition, 7, 103-107.

Hirshman, E., \& Henzler, A. (1998). The role of decision processes in conscious recollection. Psychological Science, 9, 61-66.

HiRshman, E., \& Master, S. (1997). Modeling the conscious correlates of recognition memory: Reflections on the remember-know paradigm. Memory \& Cognition, 25, 345-351

HUMPHREYS, M. S. (1978). Item and relational information: A case for context independent retrieval. Journal of Verbal Learning \& Verbal Behavior, 17, 175-187.

Humphreys, M. S., Bain, J. D., \& Pike, R. (1989). Different ways to cue a coherent memory system: A theory for episodic, semantic, and procedural tasks. Psychological Review, 96, 208-233.

JACOBY, L. L. (1991). A process dissociation framework: Separating automatic from intentional uses of memory. Journal of Memory \& Language, 30, 513-541.

JACOBY, L. L. (1998). Invariance in automatic influences of memory: Toward a user's guide for the process dissociation procedure. Journal of Experimental Psychology: Learning, Memory, \& Cognition, 24, 3 26

JACOBY, L. L., BEGG, I. M., \& ToTH, J. P. (1997). In defense of functional independence: Violations of assumptions underlying the process-dissociation procedure? Journal of Experimental Psychology: Learning, Memory, \& Cognition, 23, 484-495.

JASPER, H. A. (1958). The ten-twenty system of the international federation. Electroencepholography \& Clinical Neurophysiology, 10, $371-375$

Johnson, M. K., Hashtroudi, S., \& Lindsay, D. S. (1993). Source monitoring. Psychological Bulletin, 114, 3-28

Johnson, M. K., Kounios, J., \& NoLde, S. F. (1996). Electrophysiological brain activity and memory source monitoring. NeuroReport, 7, 2929-2932.

Johnson, R. J. (1988). The amplitude of the P300 component of the event-related potential: Review and synthesis. In P. K. Ackles, J. R. Jennings, \& M. G. H. Coles (Eds.), Advances in psychophysiology (Vol. 3, pp. 69-137). Greenwich, CT: JAI.

JoHNSON, R. J. (1995). Event-related potential insights into the neuro- 
biology of memory systems. In F. Boller \& J. Grafman (Eds.), Handbook of neuropsychology (Vol. 10, pp. 135-163). Amsterdam: Elsevier. JoORDENS, S., \& MERIKLE, P. M. (1993). Independence or redundancy? Two models of conscious and unconscious influences. Journal of Experimental Psychology: General, 122, 462-467.

KUČERA, H., \& FrANCIS, W. N. (1967). Computational analysis of present-day American English. Providence, RI: Brown University Press.

Kutas, M., \& Hillyard, S. A. (1980). Reading senseless sentences: Brain potentials reflect semantic incongruity. Science, 207, 203-205.

Kutas, M., \& VAN PetTen, C. (1988). Event-related brain potential studies of language. In P. K. Ackles, J. R. Jennings, \& M. G. H. Coles (Eds.), Advances in psychophysiology (Vol. 3, pp. 139-187). Greenwich, CT: JAI.

Lehman, D., \& Skrandies, W. (1985). Spatial analysis of evoked potentials in man-A review. Progress in Neurobiology, 23, 227-250.

MANDLER, G. (1980). Recognizing: The judgment of previous occurrence. Psychological Review, 87, 252-271.

McCarthy, G., \& WoOD, C. C. (1985). Scalp distributions of eventrelated potentials: An ambiguity associated with analysis of variance models. Electroencepholography \& Clinical Neurophysiology, 62, 203-208.

McClelland, J. L., \& Chappell, M. (1998). Familiarity breeds differentiation: A subjective-likelihood approach to the effects of experience in recognition memory. Psychological Review, 105, 724-760.

MCELrEe, B., DOLAN, P. O., \& J JCOBY, L. L. (1999). Isolating the contributions of familiarity and source information to item recognition A time-course analysis. Journal of Experimental Psychology: Learning, Memory, \& Cognition, 25, 563-582.

MURDOCK, B. B. (1982). A theory of the storage and retrieval of item and associative information. Psychological Review, 89, 609-626.

Noldy-Cullum, N. E., \& Stelmack, R. M. (1987). Recognition memory for pictures and words: The effect of incidental and intentional learning on $\mathrm{N} 400$. Electroencepholography \& Clinical Neurophysiology, 40 (Suppl.), 350-354.

NunEZ, P. L. (1981). Electrical fields of the brain. New York: Oxford University Press.

Paller, K. A., \& Kutas, M. (1992). Brain potentials during memory retrieval provide neurophysiological support of the distinction between conscious recollection and priming. Journal of Cognitive Neuroscience, 4, 375-391.

Paller, K. A., Kutas, M., \& McIsaac, H. K. (1995). Monitoring conscious recollection via the electrical activity of the brain. Psychological Science, 6, 107-111.

Picton, T. W., Lins, O. G., \& SCHERG, M. (1995). The recording and analysis of event-related potentials. In F. Boller \& J. Grafman (Eds.), Handbook of neuropsychology (Vol. 10, pp. 3-73). Amsterdam: Elsevier.

Rajaram, S., \& RoEDiger, H. L., III (1997). Remembering and knowing as states of consciousness during retrieval. In J. D. Cohen \& J. W. Scholler (Eds.), Scientific approaches to consciousness (pp. 213-240). Mahwah, NJ: Erlbaum.

RATCLIFF, R., \& MCKOON, G. (1989). Similarity information versus relational information: Differences in time course of retrieval. Cognitive Psychology, 21, 139-155.

Ratcliff, R., Van Zandt, T., \& McKoon, G. (1995). Process dissociation, single-process theories, and recognition memory. Journal of Experimental Psychology: General, 124, 352-374.

REED, A. V. (1973). Speed-accuracy tradeoff in recognition memory. Science, 181, 574-576.

Richardson-Klavehn, A., \& Gardiner, J. (1995). Retrieval volition and memorial awareness in stem completion: An empirical analysis. Psychological Research, 57, 166-178.

Richardson-Klavehn, A., Gardiner, J., \& Java, R. I. (1996). Memory: Task dissociations, process dissociations and dissociations of consciousness. In G. Underwood (Ed.), Implicit cognition (pp. 85158). Oxford: Oxford University Press.

RoEDiger, H. L., III, \& MCDermott, K. B. (1995). Creating false memories: Remembering words not presented in lists. Journal of Experimental Psychology: Learning, Memory, \& Cognition, 21, 803-814.

RotelLo, C. M., \& HeIT, E. (1999). Two-process models of recognition memory: Evidence for recall-to-reject? Journal of Memory \& Language, 40, 432-453.
RuGG, M. D. (1990). Event-related brain potentials dissociate repetition effects of high- and low-frequency words. Memory \& Cognition, 18, 367-379.

RuGG, M. D. (1995). ERP studies of memory. In M. D. Rugg \& M. G. H. Coles (Eds.), Electrophysiology of mind (pp. 132-170). New York: Oxford University Press.

RugG, M. D., Cox, C. J. C., Doyle, M. C., \& Wells, T. (1995). Eventrelated potentials and the recollection of low and high frequency words. Neuropsychologia, 33, 471-484.

RugG, M. D., \& DoYLE, M. C. (1992). Event-related potentials and recognition memory for low- and high-frequency words. Journal of Cognitive Neuroscience, 5, 69-79.

Rugg, M. D., Mark, R. E., Walla, P., Schloerscheidt, A. M., Birch, C. S., \& AlLAN, K. (1998). Dissociation of the neural correlates of implicit and explicit memory. Nature, 392, 595-598.

RugG, M. D., \& NAGY, M. E. (1989). Event-related potentials and recognition memory for words. Electroencephalography \& Clinical Neurophysiology, 72, 395-406.

RugG, M. D., Schloerscheidt, A. M., Doyle, M. C., Cox, C. J. C., \& Patching, G. R. (1996). Event-related potentials and the recollection of associative information. Cognitive Brain Research, 4, 297 304.

Rugg, M. D., Schloerscheidt, A. M., \& Mark, R. E. (1998). An electrophysiological comparison of two indices of recollection. Journal of Memory \& Language, 39, 47-69.

SCHACTER, D. L. (1987). Implicit memory: History and current status. Journal of Experimental Psychology: Learning, Memory, \& Cognition, 13, 501-518.

SCHACTER, D. L., Bowers, J., \& Booker, J. (1989). Intention, awareness, and implicit memory: The retrieval intentionality criterion. In S. Lewandowsky, J. C. Dunn, \& K. Kirsner (Eds.), Implicit memory: Theoretical issues (pp. 47-65). Hillsdale, NJ: Erlbaum.

Senkfor, A. J., \& Van Petten, C. (1998). Who said what? An eventrelated potential investigation of source and item memory. Journal of Experimental Psychology: Learning, Memory. \& Cognition, 24. 1005-1025.

Shiffrin, R. M., \& Stervers, M. (1997). A model of recognition memory: REM-Retrieving effectively from memory. Psychonomic Bulletin \& Review, 4, 145-166.

SMITH, M. E. (1993). Neurophysiological manifestations of recollective experience during recognition memory judgments. Journal of Cognitive Neuroscience, $5,1-13$.

SMith, M. E., \& Halgren, E. (1989). Dissociation of recognition memory components following temporal lobe lesions. Journal of Experimental Psychology: Learning, Memory, \& Cognition, 15, 50-60.

Srinivasan, R., Nunez, P. L., Silberstein, R. B., Tucker, D. M., \& CADUSCH, P. J. (1996). Spatial sampling and filtering of EEG with spline-Laplacians to estimate cortical potentials. Brain Topography, 8, 355-366.

Tendolkar, I., Doyle, M. C., \& RugG, M. D. (1997). An event-related potential study of retroactive interference in memory. NeuroReport, 8, 501-506.

Тотн, J. P. (1995). Unintentional influences and opposition: A reply to Graf. European Journal of Cognitive Psychology, 7, 233-237.

Tотн, J. P. (1996). Conceptual automaticity in recognition memory: Levels-of-processing effects on familiarity. Canadian Journal of Experimental Psychology, 50, 123-138.

ToTh, J. P., REINGOLD, E. M., \& JACOBY, L. L. (1994). Toward a redefinition of implicit memory: Process dissociations following elaborative processing and self-generation. Journal of Experimental Psychology: Learning, Memory, \& Cognition, 20, 290-303.

Toth, J. P., Reingold, E. M., \& JACOBY, L. L. (1995). A response to Graf and Komatsu's (1994) critique of the process dissociation procedure: When is caution necessary? European Journal of Cognitive Psychology, 7, 113-130

Trott, C. T., Friedman, D., Ritter, W., \& Fabiani, M. (1997). Item and source memory: Differential age effects revealed by eventrelated potentials. NeuroReport, 8, 3373-3378.

TuCKER, D. M. (1993). Spatial sampling of head electrical fields: The geodesic sensor net. Electroencephalography \& Clinical Neurophysiology, 87, 154-163.

Tucker, D. M., Liotti, M., Potts, G. F., Russell, G. S., \& Posner, 
M. I. (1994). Spatiotemporal analysis of brain electrical fields. Human Brain Mapping, 1, 134-152.

Van Petten, C., Kutas, M., Kluender, R., Mitchiner, M., \& MCISAAC, H. (1991). Fractionating the word repetition effect with eventrelated potentials. Journal of Cognitive Neuroscience, 3, 131-150.

Wilding, E. L., Doyle, M. C., \& RugG, M. D. (1995). Recognition memory with and without retrieval of context: An event-related potential study. Neuropsychologia, 33, 743-767.

Wilding, E. L., \& RUGG, M. D. (1996). An event-related potential study of recognition memory with and without retrieval of source. Brain, 119, 889-905.

WILDING, E. L., \& RUGG, M. D. (1997a). Event-related potential and the recognition memory exclusion task. Neuropsychologia, 35, 119-128.

WILDING, E. L., \& RUGG, M. D. (1997b). An event-related potential study of recognition memory for words spoken aloud or heard. Neuropsychologia, 35, 1185-1195.

YONELINAS, A. P. (1994). Receiver-operating characteristics in recognition memory: Evidence for a dual-process model. Journal of Experimental Psychology: Learning, Memory, \& Cognition, 20, 1341-1354.

YONELINAS, A. P. (1997). Recognition memory ROCs for item and associative information: The contribution of recollection and familiarity. Memory \& Cognition, 25, 747-763.

\section{NOTES}

1. The "parietal old/new effect" has also been labeled the "late ERP old/new effect" (Rugg, 1995), the "P300 old/new difference" (Johnson, 1995), and the "P600 old/new effect" (Curran, 1999; Rugg \& Doyle, 1992).
2. It is unclear whether the $\mathrm{N} 400$ and FN400 are distinct components or a single component with task-varying topography. The $\mathrm{N} 400$ has a centro-parietal maximum in the classic semantic studies (reviewed by Kutas \& Van Petten, 1988) and many studies of recognition memory and word repetition (e.g., Besson, Kutas, \& Van Petten, 1992; Rugg \& Nagy, 1989; Smith \& Halgren, 1989; Van Petten, Kutas, Kluender, Mitchiner, \& McIsaac, 1991), but a more anterior distribution has been observed with single-word studies fostering semantic processing (Bentin, Mouchetant-Rostaing, Giard, Echallier, \& Pernier, 1999).

3. The primary consequence of the Experiment 1 event timing error is additional trial-level latency variability $( \pm 15 \mathrm{msec})$ that could add noise to the stimulus-locked averaging process used to compute ERPs. This random noise may depress ERP amplitudes somewhat, but it would not bias comparisons between conditions. The present strategy of replicating all effects across both experiments lessens the possibility that the timing error skewed the results.

4. Data were discarded from a large number of subjects across both experiments $(n=20)$. The subjects were discarded because of excessive eye movements $(n=9)$, computer malfunction $(n=3)$, improperly fitting Nets $(n=2)$, insufficient similar[yes] trials (due to high accuracy, $n=1$; or conservative response bias, $n=1$ ), a fire alarm, itching from the electrolytic solution, body movement, or being substantially older than the rest of the college-aged sample ( 42 years).

5. Curran (1999) used eight larger spatial regions with unequal numbers of electrode in each region. The hexagonal regions were preferred for the present analyses because they are more uniform. However, the primary effects described with the present hexagonal regions were also observed with Curran's larger regions. Thus, the present effects are not overly sensitive to the exact locations chosen for analysis.

\begin{abstract}
APPENDIX
The data were re-referenced with respect to the average of the two mastoid recording channels to facilitate comparison with mastoid-referenced ERPs published elsewhere. Figure A1 shows mastoid-referenced ERPs at 15 standard locations from the international 10-20 system (Jasper, 1958). The 400-800-msec parietal effects over PS regions were very similar in the average-referenced ERPs (Figure 2, LPS and RPS) and the mastoid-referenced ERPs (Figure A1, P3 and P4). The AS FN400 pattern (300-500 msec, new[no] < similar[yes] = studied[yes]; Figures 2 and 3) was less discernable in the mastoid-referenced ERPs. The 10-20 locations nearest to the AS regions were F3 and F4 (Sensor Net channels 25 and 124). At these locations, mastoid-referenced amplitudes were more positive in the studied[yes] condition than in the other two conditions (300-500 msec, Figure Al). Closer inspection of the mastoid-referenced data revealed that only a subset of the AS channels (channels 12,13, and 21; see Figure 1) showed the same pattern as that observed with the average-reference. The mean mastoid-referenced amplitudes (300-500 msec) across these three channels in each condition were new[no] $=-1.64 \mu \mathrm{V}$, similar[yes] $=-0.87 \mu \mathrm{V}$, and studied[yes] $=-0.40 \mu \mathrm{V}$. Paired $t$ tests across both experiments showed that mean voltage was more negative in the new[no] condition than in either the similar[yes] condition $[t(51)=2.43, S E=0.32, p<.05]$ or the studied[yes] condition $[t(51)=3.51, S E=$ $0.35, p<.001]$. Mastoid-referenced FN400 voltage did not significantly differ between the studied[yes] and similar[yes] conditions $[t(51)=1.40, S E=0.33, p=.17]$. This pattern of mean differences is qualitatively similar to those observed over AS regions in the average-referenced ERPs (new[no] $<$ similar[yes] $=$ studied[yes]). However, the FN400 pattern (and its dissociation from the parietal effects) may not have been readily observed with mastoid-referenced ERPs recorded from limited 10-20 locations (as shown in Figure $\mathrm{A} 1$ ).
\end{abstract}



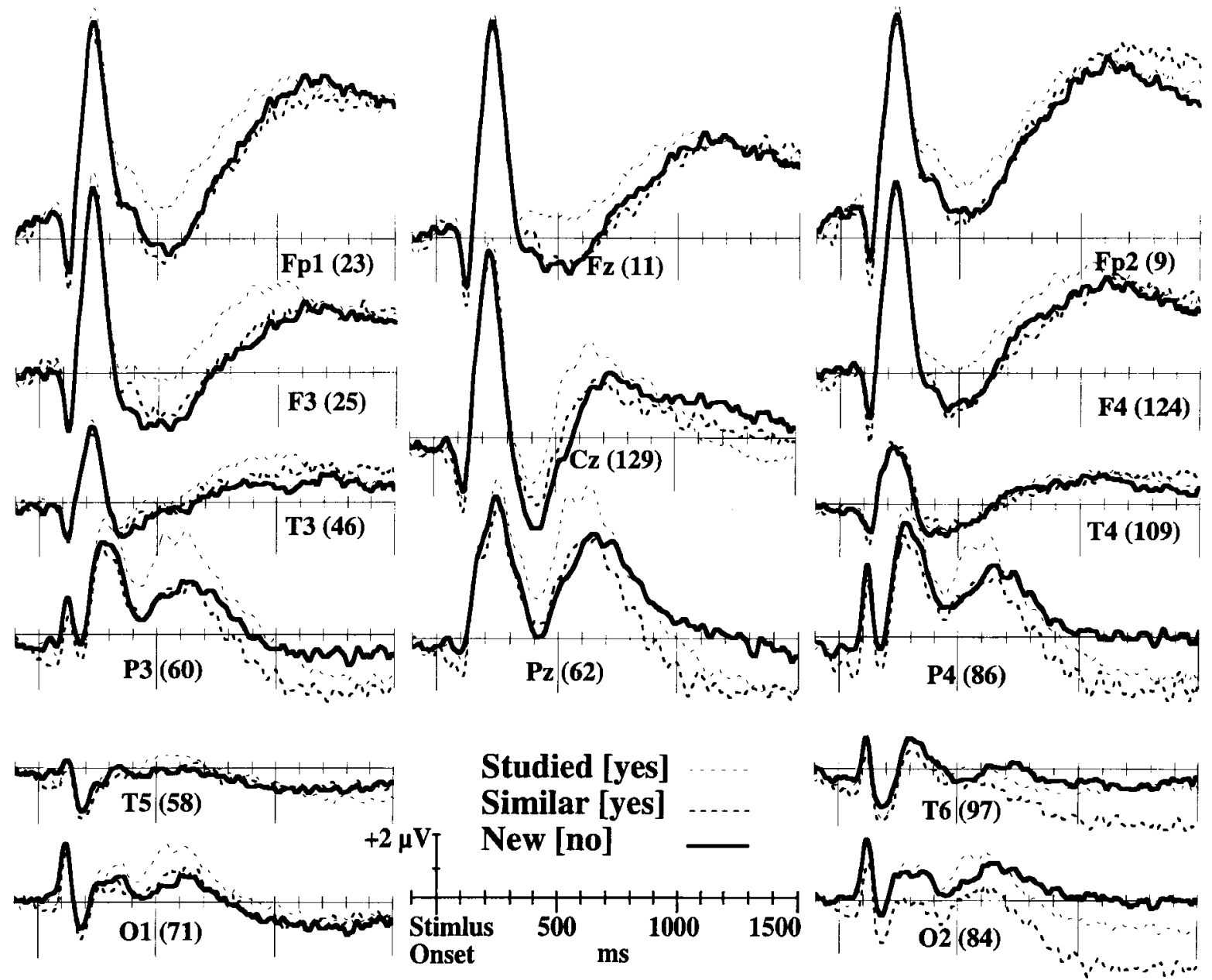

Figure A1. Mastoid-referenced ERPs from the studied[yes], similar[yes], and new[no] conditions (Experiments 1 and 2 combined). Each channel is identified by its nearest 10-20 system label along with parenthetical numbers corresponding to the sensor numbers in Figure 1. 